\title{
Total Prostatectomy within 6 Weeks of a Prostate Biopsy: Is it Safe?
}

\author{
Kishore T. Adiyat, Manoharan Murugesan, Devendar Katkoori, Ahmed Eldefrawy, Mark S. \\ Soloway
}

Department of Urology, Miller School of Medicine, University of Miami, Miami, Florida, USA

\begin{abstract}
Purpose: Many urologists recommend a six-week time interval between a prostate biopsy and a total prostatectomy (TP) to allow the biopsy induced inflammation to subside. Our aim was to assess whether the time interval between prostate biopsy and TP has an impact on the surgical outcome.

Materials and Methods: A retrospective analysis was performed on data from patients who underwent a TP by a single surgeon from 1992 to 2008 . The patients were divided into two groups according to the time interval between biopsy and TP, Group $1 \leq 6$ weeks and Group $2>6$ weeks. Relevant perioperative variables and outcome were analyzed.

Results: 923 patients were included. There was a significant difference between the two groups in the surgeons' ability to perform a bilateral nerve sparing procedure. Those who had a TP within six weeks of the biopsy were less likely to have a bilateral nerve sparing procedure. No significant difference was noted in the other variables, which included Gleason score, surgical margin status, estimated blood loss, post-operative infection, incontinence, erectile function, and biochemical recurrence.

Conclusions: TP can be safely performed without any increase in complications within 6 weeks of a prostate biopsy. However, a TP within six weeks of a biopsy significantly reduced the surgeon's perception of whether a bilateral nerve sparing procedure was performed.
\end{abstract}

Key words: prostatic neoplasms; biopsy; prostatectomy; outcomes

Int Braz J Urol. 2010; 36: 177-82

\section{INTRODUCTION}

In the United States, it is estimated that 192,280 men will be diagnosed with prostate cancer in 2009 (1). Total prostatectomy (TP) is the most common treatment for organ confined prostate cancer (2). We prefer the term "Total prostatectomy" instead of "radical prostatectomy" as we find it a more appropriate term to describe the procedure (3). Transrectal ultrasound (TRUS) guided biopsy with peri-prostatic nerve block has been the preferred modality for diagnosing prostate cancer (3). TP is typically deferred for six to eight weeks following a biopsy (4). The hypothesis is that there is an inflammatory response to the biopsy and administration of local anesthesia (4). This inflammation may take several weeks to subside (4). However, under several circumstances the TP may be performed earlier without this waiting period. The objective of this study was to assess whether the time interval between prostate biopsy and total prostatectomy has an impact on the surgical outcome. 


\section{MATERIALS AND METHODS}

We performed a retrospective analysis of 1,943 patients who underwent TP at our institution by one surgeon between 1992 and 2008. The clinical, operative and pathological details were entered into an Institutional Review Board approved database and analyzed. The patients were divided into two groups according to the time interval between biopsy and TP, Group $1 \leq 6$ weeks and Group $2>6$ weeks. We excluded patients who received neoadjuvant androgen ablation therapy, salvage TP and where the date of biopsy was unavailable. The groups were compared for preoperative and pathological parameters. Outcome variables analyzed included estimated blood loss, nerve sparing procedure, surgical margin status, Gleason score, infection, continence, erectile function $(\mathrm{EF})$, biochemical recurrence and mean follow-up. The ability to perform a nerve sparing procedure was assessed based on the surgeon's operative report. At the conclusion of the TP, the surgeon indicated whether or not one or both neurovascular bundles appeared intact. This was based on the appearance of prostatic bed and operative site. A comment was always made as to whether one or more neurovascular bundles were spared. Patients were followed-up at 6 weeks, 3 months and every 6 months thereafter. $\mathrm{EF}$ and continence were evaluated at 3 and 6 months and 6-monthly by the surgeon or by using an annual questionnaire mailed to the patient. During the interview, all patients were asked the same questions to evaluate EF. Potency was defined as "EF sufficient for intercourse with or without a phosphodiesterase-5 inhibitor". Continence was defined as "never wearing a pad". More recently, assessment of EF was done by using the Sexual Health Inventory for Men questionnaire and continence was assessed by the International Consultation on Incontinence questionnaire $(5,6)$. EF and continence at completion of second year followup was used to code the status of each patient for analyzing continence and EF. In addition, EF was assessed only in patients who were potent before surgery and had a nerve sparing procedure. Biochemical recurrence was defined as a PSA $\geq 0.2 \mathrm{ng} / \mathrm{mL}$.

Statistical analysis was performed using SPSS Version 16.0. Student's-t-test was used to compare continuous variables. Cross tabulation with Chi square test and Fisher's exact test were used to compare categorical variables. The significance value was set at a two-sided $\mathrm{p} \leq 0.05$.

\section{RESULTS}

Out of 1,943 patients $336(17.5 \%)$ had neoadjuvant hormonal therapy, 23 (1.2\%) had radiotherapy and in 661 (34\%) patients the date of biopsy was not available in the database. After excluding these patients, 923 patients met the inclusion criteria. A total of $123(13 \%)$ were in Group 1 and 800 (87\%) in Group 2. The mean time to surgery following biopsy in Group 1 and 2 was $30 \pm 9$ and $91 \pm 39$ days respectively. The median time interval in Group 1 was 32 days and in Group 2 was 82 days. No significant difference was noted between the groups when comparing age, clinical stage and preoperative biopsy findings (Table-1). There was a significant difference between the groups in the surgeon's report as to whether a nerve sparing procedure was performed $(\mathrm{P}=0.009)$ (Table-2). Those who had TP earlier than six weeks of a prostate biopsy were considered less likely to have a bilateral nerve sparing procedure. No significant difference was found in the other variables, which included estimated blood loss, wound infection, Gleason score, a positive surgical margin, continence, erectile function and clinical/biochemical recurrence.

\section{COMMENTS}

The vast majority of men with clinically localized prostate cancer do not have any symptoms (7). Many, if not most are overwhelmed emotionally following the diagnosis of prostate cancer. Patients are confronted by the prospect of changes in their life span, body image, and personal relationships $(8,9)$. Prostate cancer is usually diagnosed by a transrectal ultrasound guided biopsy (10) and typically the results are obtained within 72 hours. The diagnostic process is stressful and has been shown to be associated with an increase in serum cortisol (11). Patients who have been newly diagnosed with a cancer often have numerous short term problems which must be confronted $(12,13)$. Apprehensions encountered by patients are 
Table 1 - Comparison of preoperative variables.

\begin{tabular}{|c|c|c|c|}
\hline & I $(\leq 6$ weeks $)$ & II (> 6 weeks $)$ & p Value \\
\hline No. patients (\%) & $123(13)$ & $800(87)$ & \\
\hline Mean Age & $61 \pm 7$ & $60 \pm 8$ & $0.3^{*}$ \\
\hline Mean total PSA at diagnosis & $6.8 \pm 3.5$ & $7 \pm 5$ & $0.65^{*}$ \\
\hline Mean biopsy Gleason score $( \pm \mathrm{SD})$ & $6.45( \pm 1)$ & $6.36( \pm 0.9)$ & $0.37 *$ \\
\hline Biopsy Gleason group N (\%) & & & 0.13 \\
\hline 6 or less & $65(53 \%)$ & $496(62 \%)$ & \\
\hline 7 & $46(37.5 \%)$ & $231(29 \%)$ & \\
\hline 8 or more & $12(9.5 \%)$ & $71(9 \%)$ & \\
\hline Mean number of biopsy cores & $9.5 \pm 3$ & $9 \pm 3$ & $0.35^{*}$ \\
\hline Clinical T-Stage N (\%) & & & 0.45 \\
\hline $\mathrm{T} 1$ & $80(65 \%)$ & $539(67.5 \%)$ & \\
\hline $\mathrm{T} 2$ & $41(33 \%)$ & $241(30)$ & \\
\hline $\mathrm{T} 3$ & $2(1.5 \%)$ & $20(2.5 \%)$ & \\
\hline
\end{tabular}

$S D=$ standard deviation, ${ }^{*}$ Student-t-test.

described as the "7 D's": death, dependency, disfigurement, disruption of social relationships, disability (interference with educational, work, or leisure roles), discomfort (pain), and disengagement (returning to a normal lifestyle from the patient role) (14). According to the present standard of practice, patients are generally requested to wait for at least 6 weeks following a prostate biopsy before proceeding with TP. In the modern era most patients have easy access to virtually limitless health and medical information thus enabling them to understand their disease and decide amongst various treatment modalities. In these circumstances, a waiting period of 6 weeks can lead to considerable mental anguish. This could be considered a drawback of surgery compared to other modalities. Garsson et al. have demonstrated the effect of psychological intervention on a positive outcome in cancer patients (15). In this context, a reduction in the waiting interval might affect the outcome with regard to patients' quality of life.

Traditionally, surgery is performed 6 to 8 weeks following a needle biopsy of the prostate and a minimum of 12 weeks following a transurethral resection of the prostate (4). It is hypothesized that this delay enables inflammatory adhesions or hematoma to resolve thereby maintaining anatomic relationships between the prostate and the surrounding structures
(4). The tissue reaction subsequent to the peri-prostatic nerve block and biopsies may make preservation of the neurovascular bundles more difficult. It might also lead to a potentially serious complication such as rectal injury. When surgery was performed within 6 weeks of biopsy, we have occasionally noted that the apical dissection of the neurovascular bundles is more difficult. Whether this is related to the biopsies or the peri-prostatic nerve blockade is unclear. Although the local anesthetic is generally placed near the base of prostate it tends to diffuse in the peri-prostatic space and involve the apex and this inflammatory reaction is variable.

Lee et al. reported that the interval between biopsy and TP did not have an effect on the immediate post operative outcome (16). In our study we did not find an additional increase in blood loss when the surgery was performed within 6 weeks of a prostate biopsy. The perioperative complications were similar in both groups. There was no significant difference in biochemical recurrence between Group 1 (14\%) and Group $2(11 \%)(P=0.28)$. However, a significant difference was noted between the groups $(\mathrm{P}=0.009)$ in ability to perform a bilateral nerve sparing procedure. A bilateral nerve sparing procedure was performed in only $49 \%$ of patients in Group 1 compared to $61 \%$ of patients in Group 2. In their study on 2,996 patients, 
Table 2 - Comparison of surgical, functional and oncologic outcome.

\begin{tabular}{lccc}
\hline & I $(\leq 6$ weeks $)$ & II $(>6$ weeks $)$ & p Value \\
\hline Mean EBL $( \pm$ SD) in $\mathrm{mL}$ & $493( \pm 288)$ & $477( \pm 300)$ & 0.6 \\
Mean wet weight of prostate $( \pm \mathrm{SD})$ & $47( \pm 18)$ & $46( \pm 21)$ & 0.76 \\
Pathologic Gleason & $6.5( \pm 1.2)$ & $6.9( \pm 0.8)$ & 0.08 \\
Bilateral nerve sparing $(\%)(\mathrm{n}=847)$ & & & \\
$\quad$ Bilateral & $59(49)$ & $441(61)$ & 0.009 \\
$\quad$ Unilateral & $21(17)$ & $119(16.5)$ & 0.44 \\
$\quad$ None & $41(34)$ & $166(22.5)$ & 0.007 \\
No. infections $(\%)$ & $1(0.8)$ & $7(0.9)$ & 0.7 \\
No. of positive margin $(\%)$ & $45(35)$ & $229(28.5)$ & 0.09 \\
Continence at 2 years(\%) $(\mathrm{n}=785)$ & & $654(95)$ & 0.12 \\
$\quad$ Continent & $90(92)$ & $33(5)$ & \\
$\quad$ Incontinent* & $18(8)$ & $293(73)$ & 0.43 \\
Potency (\%) at 2 years $(\mathrm{n}=458)^{\#}$ & & $109(27)$ & \\
$\quad$ Potent & $38(68)$ & $93(11.5)$ & 0.284 \\
$\quad$ Impotent & $18(32)$ & $40( \pm 39)$ & $<0.05$ \\
No. of biochemical recurrence (\%) & $17(14)$ & $53.5( \pm 49)$ & \\
Mean follow-up in months $( \pm \mathrm{SD})$ &
\end{tabular}

* wearing a pad, "potency was calculated for those patients who had nerve sparing surgery; EBL = estimated blood loss; SD = standard deviation.

Eggner et al. concluded that a shorter interval between biopsy and TP did not adversely affect surgical outcome (17). They analyzed radical prostatectomy conducted before 4 and 6 weeks after a prostate biopsy and did not find a difference in operating time, estimated blood loss, surgical margin status, urinary incontinence or EF (17). Similar to our study, they noted a significant reduction in the proportion of patients who had a nerve sparing procedure in the early surgery group (17). Although the specific explanation for this finding is still unknown, the data from both the studies indicates that a cautious approach is needed. Further, prospective studies are needed to confirm and analyze factors leading to this finding.

Our study has some limitations. It is a retrospective study spanning fifteen years. The biopsy date was unavailable for a significant number of patients and hence they were excluded. The reason for operating within 6 weeks could not be precisely documented.
However, at our institution we do not follow a rigid timeline for advising TP, and typically other factors such as availability of the operating room, patient anxiety weigh in when scheduling the surgery.

\section{CONCLUSIONS}

It is feasible to perform a TP within 6 weeks after a prostate biopsy without an increase in complications. In our experience, TP within 6 weeks of a biopsy limits the ability to perform a bilateral nerve sparing procedure. However, early surgery did not affect the potency rate in men who had a nerve sparing procedure. In this context it would be prudent to perform early TP only in carefully selected cases when there is a high risk of progression and potency is not of concern. When surgery is performed before six weeks patients should be counseled about the 
decreased chances of preserving the neurovascular bundles.

\section{ACKNOWLEDGEMENTS}

"CURED" and Mr. Vincent A. Rodriguez.

\section{CONFLICT OF INTEREST}

None declared.

\section{REFERENCES}

1. Jemal A, Siegel R, Ward E, Hao Y, Xu J, Thun MJ: Cancer statistics, 2009. CA Cancer J Clin. 2009; 59: 225-49.

2. Han M, Partin AW, Pound CR, Epstein JI, Walsh PC: Long-term biochemical disease-free and cancer-specific survival following anatomic radical retropubic prostatectomy. The 15-year Johns Hopkins experience. Urol Clin North Am. 2001; 28: 555-65.

3. Cooner WH, Mosley BR, Rutherford CL Jr, Beard JH, Pond HS, Terry WJ, et al.: Prostate cancer detection in a clinical urological practice by ultrasonography, digital rectal examination and prostate specific antigen. J Urol. 1990; 143: 1146-52; discussion 11524.

4. Walsh PC Partin AW: Anatomic Radical Retropubic Prostatectomy. In: Wein AJ KR, Novick AC, Partin AW, Peters CA (ed.), Campbell-Walsh Urology. 9th ed. Philadelphia, Saunders Elsevier; 2007: pp. 295678.

5. Rosen RC, Cappelleri JC, Smith MD, Lipsky J, Peña BM: Development and evaluation of an abridged, 5 -item version of the International Index of Erectile Function (IIEF-5) as a diagnostic tool for erectile dysfunction. Int J Impot Res. 1999; 11: 319-26.

6. Avery K, Donovan J, Peters TJ, Shaw C, Gotoh M, Abrams P: ICIQ: a brief and robust measure for evaluating the symptoms and impact of urinary incontinence. Neurourol Urodyn. 2004; 23: 322-30.

7. Carter HB, Allaf ME, Partin AW: Diagnosis and Staging of Prostate Cancer. In: Wein AJ KR, Novick AC, Partin, AW, Peters CA (ed.), Campbell-Walsh Urology. 9th ed. Philadelphia, Saunders Elsevier, 2007; pp. 2912-25.
8. Burke MA, Lowrance W, Perczek R: Emotional and cognitive burden of prostate cancer. Urol Clin North Am. 2003; 30: 295-304.

9. Soloway CT, Soloway MS, Kim SS, Kava BR: Sexual, psychological and dyadic qualities of the prostate cancer 'couple'. BJU Int. 2005; 95: 780-5.

10. Leite KR, Srougi M, Dall'Oglio MF, Sanudo A, Camara-Lopes LH: Histopathological findings in extended prostate biopsy with PSA $<$ or $=4 \mathrm{ng} / \mathrm{mL}$. Int Braz J Urol. 2008; 34: 283-90; discussion 290-2.

11. Gustafsson O, Theorell T, Norming U, Perski A, Ohström M, Nyman CR: Psychological reactions in men screened for prostate cancer. Br J Urol. 1995; 75: 631-6.

12. Moore KN, Estey A: The early post-operative concerns of men after radical prostatectomy. J Adv Nurs. 1999; 29: 1121-9.

13. Schag CA, Ganz PA, Wing DS, Sim MS, Lee JJ: Quality of life in adult survivors of lung, colon and prostate cancer. Qual Life Res. 1994; 3: 127-41.

14. Breitbart W, Holland JC: Psychiatric Aspects of Symptom Management. In: Cancer Patients. American Psychiatric Press, Washington, DC. 1993.

15. Garssen B, Goodkin K: On the role of immunological factors as mediators between psychosocial factors and cancer progression. Psychiatry Res. 1999; 85: 51-61.

16. Lee DK, Allareddy V, O'donnell MA, Williams RD, Konety BR: Does the interval between prostate biopsy and radical prostatectomy affect the immediate postoperative outcome? BJU Int. 2006; 97: 48-50.

17. Eggener SE, Yossepowitch O, Serio AM, Vickers AJ, Scardino PT, Eastham JA: Radical prostatectomy shortly after prostate biopsy does not affect operative difficulty or efficacy. Urology. 2007; 69: 1128-33.

\section{Accepted after revision:}

October 5, 2009 


\section{EDITORIAL COMMENT}

The purpose of this study was to assess the impact of time interval, $\leq 6$ weeks (Group I) compared to $>6$ weeks (Group II), between prostate biopsy and total prostatectomy (TP) on the surgical outcome including the ability to perform nerve sparing procedure in patients with organ confined prostate cancer.

In the PSA era, most of patients were diagnosed by transrectal ultrasound guided biopsy. The number of core biopsy was increased from 6 cores to average of 10 to 12 cores and peri-prostatic local anesthesia become more popular. These procedures will give an impact such as more inflammation around the prostate which will hamper the subsequent surgical procedure.

This study concluded that it is safe to perform TP within 6 weeks after biopsy. However, there was a significant reduction of the surgeons' ability to perform bilateral nerve sparing procedure in this setting. These findings are supported by other studies. Lee DK et al. (reference 16 in article) reported no significant difference in peri-operative parameters as well as immediate post-operative outcome in patients with biopsy to TP intervals above and below the median which was 8 weeks. Eggener et al. (reference 17 in article) reported similar findings and also found significant less nerve sparing procedures in early TP group. Therefore, it is better to wait for 6 weeks after biopsy before doing the surgery especially if potency is of paramount important for the patient.

However, problems like fear of negative impact on disease-free progression could arise in the waiting period which might make the patients choose another treatment modality. Recently, there were 2 studies with totally more than 2600 TP performed two or more months after biopsy without any neo-adjuvant treatment $(1,2)$. These studies concluded that delays up to several months from biopsy to TP have no influence on biochemical recurrence. Hence, we could reassure the patients that this procedure has a low risk.

\section{REFERENCES}

1. Khan MA, Mangold LA, Epstein JI, Boitnott JK, Walsh PC, Partin AW: Impact of surgical delay on long-term cancer control for clinically localized prostate cancer. J Urol. 2004; 172: 1835-9.

2. Boorjian SA, Bianco FJ Jr, Scardino PT, Eastham JA: Does the time from biopsy to surgery affect biochemical recurrence after radical prostatectomy? BJU Int. 2005; 96: 773-6.

Dr. Rainy Umbas Department of Urology Dr. Cipto Mangunkusumo Hospital University of Indonesia Jakarta, Indonesia E-mail: rainy.umbas@gmail.com 